\title{
Ampliando o diálogo entre trabalhadores e profissionais de pesquisa: alguns métodos de pesquisa-intervenção para o campo da Saúde do Trabalhador
}

\author{
Broadening the dialogue between workers \\ and research professionals: some research-intervention methods \\ for the occupational health field
}

Tatiana Ramminger ${ }^{1}$

Milton Raimundo Cidreira de Athayde ${ }^{2}$

Jussara Brito $^{3}$

\footnotetext{
${ }^{1}$ Departamento de

Psicologia, Universidade

Federal Fluminense, Polo

Universitário de Volta

Redonda. R. Desembargador

Ellis Hermydio Figueira

783/Bloco A, Aterrado.

27.213-415 Volta Redonda

RJ Brasil.

tatiramminger@gmail.com

${ }^{2}$ Instituto de Psicologia,

Centro de Educação e

Humanidades,

Universidade do Estado do

Rio de Janeiro.

${ }^{3}$ Escola Nacional de Saúde

Pública Sergio Arouca,

Fundação Oswaldo Cruz.
}

\begin{abstract}
The paper discusses some methods that emphasize collective and shared analysis of the relationship established "at" and 'with" work, in a synergetic relationship with the experience of the protagonists at work. They can be characterized as research-intervention methods that make important contributions to the field of Occupational Health, some of which are developed within the scope of the Psychology of Work. Methods that use Karl Marx's "worker poll" as their benchmark, highlighting contributions from some of the Work Clinics - taking the existence of theoretical and methodological affinities and differences into consideration - such as the Italian Worker Model of the quest for health, Ergonomics in the Workplace and the Psychodynamics of Work. Subsequently, the Three-Pole Dynamic Device put forward by Ergology is discussed, as well as one of its configurations being developed in Brazil, namely the Extended Research Community.
\end{abstract}

Key words Occupational health, Mental health and work, Methodology
Resumo $O$ artigo discute alguns métodos que enfatizam formas coletivas e compartilhadas de análise das relações que se estabelecem no e com o trabalho, em relação sinérgica com a experiência dos protagonistas do trabalho. Pode-se caracterizá-los como métodos de pesquisa-intervenção que apresentam contribuições importantes para o campo da Saúde do Trabalhador, alguns dos quais desenvolvidos no âmbito da Psicologia do Trabalho. Métodos que tem como sua referência a "enquete operária" de Karl Marx, destacando-se as contribuições de algumas das Clinicas do Trabatho - considerando-se a presença de afinidades teórico-metodológicas e diferenças - como o Modelo Operário Italiano de luta pela saúde, a Ergonomia da Atividade e a Psicodinâmica do Trabalho. Em seguida, discute-se a proposta avançada pela Ergologia - o Dispositivo Dinâmico de Três Polos - e uma de suas configurações que vem sendo desenvolvida no Brasil, a Comunidade Ampliada de Pesquisa.

Palavras-chave Saúde do trabalhador, Saúde mental e trabalho, Metodologia 


\section{Introdução}

O campo denominado na América Latina por Saúde do Trabalhador insere-se na tradição dos estudos sobre a relação entre vida, saúde e trabalho, produzindo-se aí um desvio, na medida em que propõe deslocar o centro da análise do indivíduo para o processo produtivo (processo de trabalho e relações sociais) $)^{1,2}$.

Nesta variação, encontra-se o entendimento de que analisar e intervir/interferir fazem parte do mesmo processo, sem que necessariamente haja uma sequência linear. Pode-se então falar na deriva "compreender $\leftrightarrow$ transformar"3. Por outro lado, considerando-se a capacidade normativa dos viventes ${ }^{4}$, os humanos ao trabalhar, mesmo sob condições de exploração, não estão excluídos da potência afirmativa da vida. Emerge nesta cena o humano em atividade, frente a adversidades, com sua vitalidade, interessado em seu desenvolvimento, pessoal e coletivo (do ofício). Trata-se de um enigma cuja compreensão e melhor encaminhamento passam pela experiência dos protagonistas do trabalho. Assim sendo, qualquer dispositivo para compreender $\leftrightarrow$ transformar o trabalho em sua dinâmica com a saúde deve ser, sempre que possível, uma operação de coanálise. A participação dos trabalhadores - individual e coletivamente - na identificação e enfrentamento de situações geradoras de adoecimentos e acidentes tornou-se uma marca deste campo, denominado Saúde do Trabalhador, na América Latina.

Este artigo visa contribuir para a discussão metodológica (e seus pressupostos epistemológi$\cos )$, na perspectiva de qualificar uma relação dialógica ${ }^{5,6}$ entre pesquisadores profissionais e protagonistas do trabalho em análise. Busca-se fazêlo a partir de uma breve apresentação de alguns dos métodos que têm orientação epistemológica relativamente comum e dos quais temos feito uso, quais sejam, a Enquete Operária de Marx, a Análise Ergonômica do Trabalho, a Enquete da Psicodinâmica do Trabalho, as contribuições do Modelo Operário Italiano de luta pela saúde e o desenvolvimento mais recente conformado pela Ergologia, com o Dispositivo Dinâmico de Três Polos e uma de suas configurações no Brasil: a Comunidade Ampliada de Pesquisa. Com esta seleção não se ignora outras opções metodológicas e técnicas disponíveis, com algumas das quais há, inclusive, significativas interfaces ${ }^{7,8}$.

O desenvolvimento destas metodologias segue como um desafio no campo da Saúde do Trabalhador, o que se pode perceber em disser- tações, teses, eventos e livros recentes, como os organizados por Minayo-Gomes et al., sobre Saúde do Trabalhador na sociedade brasileira contemporânea ${ }^{1}$; e Assunção e Brito ${ }^{9}$, neste caso tendo como foco os trabalhadores em saúde. Outros se dedicam à questão mais específica da Saúde Mental, como o organizado por Glina e Rocha ${ }^{10}$ ou das Clínicas do Trabalho, como o organizado por Bendassoli e Soboll ${ }^{11}$.

\section{Marx e a "Enquete Operária"}

Inicia-se por um registro histórico-genealógico, incontornável: as ideias que norteiam essa linhagem metodológica passam pelo processo de produção de conhecimento encaminhado por Marx, mais explicitamente quando ele incorporou, em 1880, ao seu ousado processo de análise histórica, um empreendimento que se tornou conhecido por "Enquete Operária". Marx, com o exercício da Enquete, revelava-se em oposição à ideia de que o trabalhador ignora ou é apenas passivo frente à realidade que vive, afirmando no texto $O$ Questionário de $1880^{12}$ que "apenas eles podem descrever, com todo conhecimento de causa, os males que suportam, e de que só eles, e não os salvadores providenciais, podem energicamente remediar as misérias sociais que sofrem".

$\mathrm{Na}$ verdade, a forma de investigação denominada "enquete" fora criada nas primeiras décadas do século XIX, na Europa mais industrializada, a partir de demandas policiais-governamentais, morais e religiosas, para dar conta da emergente "questão operária", como então se designava a miséria e a periculosidade do trabalho operário. Conforme Bidet e Vatin ${ }^{13}$, desde 1830 desenvolveu-se uma tradição de descrição técnica minuciosa da indústria na Inglaterra que alimentaram a fascinação de Marx pelo maquinismo com informações decisivas para suas análises sobre o sistema técnico daquele período.

Posteriormente, estas técnicas começaram a ser utilizadas pelos chamados grupos socialistas (aqui entendidos como as forças que passaram a se contrapor à doutrina do liberalismo econômico), com o objetivo de autoconhecimento da classe operária. Temos, por exemplo, a investigação realizada por Engels ${ }^{14}$, entre 1842-1844, pelas principais cidades industriais inglesas, publicada em 1845 com o título "A situação da classe trabalhadora na Inglaterra".

Na França, o movimento de organização dos trabalhadores consegue, em 1879, realizar um Congresso Operário, em Marseille, no qual as 
teses marxistas foram vitoriosas. Foi assim que, em 1880, a pedido da Revue Socialiste, que organizava uma enquete sobre a realidade operária, Marx formulou um questionário (na forma de um questionamento) direcionado a trabalhadores do campo e da cidade, com o objetivo não apenas de levantar dados e características de sua situação de trabalho, como também de mobilizar a consciência crítica do trabalhador a respeito de sua condição de exploração. Além da publicação pela Revista foram também enviadas cópias para, nas palavras do autor, "todas as sociedades operárias, todos os grupos ou círculos socialistas e democráticos, a todos os jornais franceses" ${ }^{15}$, disponibilizando-a a todos os interessados que o solicitassem.

O questionário, com 101 questões, era dividido em quatro partes, alinhavado por um posicionamento inicial de Marx sobre a exploração capitalista, fruto de suas descobertas. A primeira solicitava e orientava uma descrição da fábrica em que trabalhavam, contemplando três grupos principais de perguntas: composição do coletivo de trabalhadores enquanto força de trabalho, estrutura da fábrica do ponto de vista técnico e condições de trabalho. A segunda parte investigava estes fatores, mas em sua dinâmica, considerando as formas de domínio e exploração; e a terceira privilegiava a questão salarial. Com esta sequência, Marx pretendia - questionando - dar subsídios de economia política suficientes para que os trabalhadores percebessem, com clareza, as formas de exploração a que estavam submetidos. Finalmente, a última parte do questionário era um convite à reflexão, solicitando informações sobre como eles já estariam se opondo, no cotidiano, à exploração.

Para melhor compreensão da forma-enquete usada por Marx, vale ressaltar alguns pontos. Primeiro, a forma interrogativa, estimulando o diálogo crítico, algo que se vai encontrar posteriormente no Brasil, com Freire e Faundez ${ }^{16}$ e Boal $^{17}$. A formulação das perguntas e sua ordenação revelam a ausência de qualquer ilusão de neutralidade; ao contrário, busca-se o rigor pela via da clareza da posição, explicitando a problemática que orienta o questionário. Uma estratégia que implica o pensamento, mobilizando o outro, exigindo que ele se mova em um raciocínio próprio, para além de uma resposta mecânica.

Thiollent ${ }^{18}$ destaca a presença de um tipo de "imposição de problemática" que oferece indicações científicas sobre o assunto e estimula o questionamento, a busca por investigar o mundo em que se vive e trabalha. E mais: para além do cam- po emocional, dos sentimentos e opiniões, na Enquete privilegia-se o processo cognitivo, tendo como objeto a lógica do capital, buscando a ruptura com o senso comum.

\section{Análise Ergonômica do Trabalho (AET)}

Ergonomia, no imediato pós-segunda guerra, na Inglaterra, foi a denominação da primeira associação (Ergonomic Research Society) que reunia profissionais de diversas disciplinas, sobretudo a Psicologia, Fisiologia e Engenharias, para um empreendimento inovador: adaptar o trabalho ao homem e não o inverso, como operava a Psicotécnica. "Filha da guerra", esta primeira Ergonomia, como tantas outras inovações produzidas a partir deste trágico acontecimento histórico, foi transportada para o mundo industrial, onde se percebiam problemas de natureza similar ${ }^{19}$.

A análise ergonômica, como nos explicam Leplat e $\mathrm{Hoc}^{20}$ e Montmollin ${ }^{21}$ tem duas grandes abordagens: uma, identificada com as experiências estadunidenses e britânicas, centrado no componente humano (human factors) do sistema homem-máquina; e outra que se desenvolveu a partir dos países francófonos, privilegiando a análise da atividade situada, expressão da interação dinâmica entre sujeito e tarefa. O objetivo da primeira abordagem é adaptar os dispositivos tecnológicos às características e limites dos seres humanos e, para tanto, prioriza métodos científicos baseados na generalização e quantificação sem, necessariamente, ter que recorrer a uma observação ou discussão do trabalho com os operadores. Já a segunda, traz como uma das principais contribuições a diferenciação entre trabalho prescrito e trabalho real (avançando posteriormente para os conceitos de tarefa e atividade), sendo imprescindível a análise da situação concreta de trabalho.

Para Montmollin ${ }^{21}$ seria mais preciso falar em Ergonomias, complementares, mas não sem contradições. A Ergonomia dos componentes humanos (Human Factors) seria uma "ergonomia de primeiros socorros" que considera as características dos postos de trabalho (iluminação, calor, umidade, ruídos, assentos, etc.), independente daqueles que os ocupam. Já a Ergonomia da Atividade (EAt) permite ao trabalhador interessar-se por sua "atividade real, temporal, complexa, rara, aparentemente inventiva e, às vezes, imperfeita"22. Ao demonstrar que a situação real de trabalho jamais é apenas o cumprimento de regras pré-estabelecidas, conforme acreditava a gerência racionalizadora taylorista, por exemplo, 
esta Ergonomia apontou que em qualquer atividade, mesmo naquela considerada mais simples, mecânica ou manual, sempre há uma operação inteligente e uma intensa atividade mental.

No plano metodológico, para dar sustentação à ação ergonômica, desenvolveu-se a Análise Ergonômica do Trabalho (AET), cujo princípio é "compreender para transformar" ${ }^{23}$. Inicia-se pela análise da demanda, interrogando os problemas apresentados pelos contratantes, instruindo-a e definindo os objetos da ação. O objetivo é dar visibilidade às dificuldades e estratégias desenvolvidas para gerir a distância entre a tarefa prescrita e atividade, aí constituindo o chamado ponto de vista da atividade ${ }^{24}$. Um ponto de vista dentre outros, como o dos resultados, das condições de produção, mas que em regra encontra-se excluído ou inteiramente subordinado aos demais. Constituindo-o, é preciso colocá-lo em confrontação com os demais.

Como afirma Teiger $^{19}$, a atividade de trabalho não é um objeto dado para um investigador que o coletaria, mas um objeto a ser construído e reconstruído, em parceria com os protagonistas do trabalho em análise. Isto porque a atividade não se limita àquilo que pode ser diretamente observado, registrado e quantificado, sendo essencial a confrontação e a verbalização do operador. Conforme esclarece Botechia ${ }^{25}$ :

[...] a verdadeira ruptura com a Ergonomia britânica e americana acontece quando a palavra passa a ser considerada como um comportamento carregado de sentido. Nesta direção, a Análise Ergonômica do Trabalho deve levar em conta a observação dos comportamentos motores e também das trocas verbais estabelecidas em uma situação de trabalho.

A AET tem como ponto de partida a existência de uma demanda, seguida por negociações, por uma análise global, pela análise da demanda e sua reformulação, por focalizações e um prédiagnóstico, contemplando observações sistemáticas no curso da atividade e a confrontação com os trabalhadores, buscando a elaboração conjunta de alternativas para a transformação dos problemas identificados na situação de trabalho analisada. O processo de restituição e validação dos resultados apresentados no diagnóstico preliminar é fundado no diálogo construtivo da confrontação de compreensões, o que configura um verdadeiro processo de coprodução de conhecimentos. De fato, para Daniellou ${ }^{26,27}$, a validação se dá em dois atos: (a) no contexto da intervenção, por meio de restituições sucessivas dos resultados aos sujeitos participantes buscando eviden- ciar os processos subjacentes à problemática de análise; (b) fora do contexto sociotécnico de produção, ou seja, nos fóruns científicos norteados por regras da práxis da Ergonomia. Todo este itinerário metódico conflui para chegar a um diagnóstico ergonômico, apresentado em um relatório final contendo um caderno de encargos, que conduz à negociação da implementação ergonômica para a transformação positiva do trabalho.

$\mathrm{O}$ que caracteriza essa abordagem clínica $^{28}$ em relação a outros modos de analisar o trabalho é a exigência da presença do pesquisador lá onde o trabalho acontece, constituindo-se o ponto de vista da atividade, fazendo uso da confrontação das observações dos pesquisadores com as vivências dos trabalhadores, possibilitando tanto o diagnóstico (compreensão), como o desenvolvimento (transformação) dos modos de trabalhar. No que diz respeito a seus resultados, Daniellou ${ }^{26}$ sinaliza que não há uma relação imediata entre conhecimento, diagnóstico, ação e prognóstico, mas espera-se ao menos transformar as representações dos atores visando a transformação das situações.

\section{Enquete como estratégia metódica da Psicodinâmica do Trabalho}

Junto com a Ergonomia, a Psicopatologia do Trabalho formou a base inicial mais influente da tradição das clínicas do trabalho desenvolvidas na França. Emergindo no pós-segunda-guerra por psiquiatras como Le Guillant, Sivadon, Veil e Fernandez-Zöila, a Psicopatologia do Trabalho (PPT) concentrou sua atenção nos modos como o trabalho capitalista contribuía para o adoecimento psíquico ${ }^{29-31}$. O projeto mais influente, inicialmente assumido por Le Guillant, era o de chegar a um mapeamento da formas de adoecimento ligadas ao trabalho capitalista. Seus referenciais teóricos e metodológicos foram se diferenciando, da abordagem do Condicionamento Clássico pavloviano à Fenomenologia e mesmo à Gestalt ${ }^{32,33}$.

Já no final dos anos 1970, a "segunda geração" da Psicopatologia do Trabalho, especialmente a corrente AOCIP liderada por Dejours, descobriu que os trabalhadores não se revelavam passivos frente aos constrangimentos organizacionais, desenvolvendo sistemas defensivos coletivos (de tipo estratégico e ideológico) para se proteger destes constrangimentos e dos riscos de adoecerem. O foco, portanto, deixa de ser a busca de detecção das doenças mentais ocasionadas pelo trabalho e passa a ser o sofrimento e as de- 
fesas contra o sofrimento no trabalho, ou ainda, a normalidade e não a doença mental ${ }^{34}$. Aos poucos, Dejours inverte a pergunta-chave da Psicopatologia do Trabalho, questionando não mais sobre como, em que medida, o trabalho "enlouquece", mas justamente sobre o modo como os trabalhadores, mesmo quando sujeitos às mais diversas pressões patogênicas no trabalho, conseguem evitar a descompensação, os transtornos mentais graves, o adoecimento.

Como o próprio autor explica:

Simultaneamente, era a 'normalidade' que surgia como enigma central da investigação e da análise. Normalidade que ocorre, de saída, como equilíbrio instável, fundamentalmente precário, entre o sofrimento e as defesas contra o sofrimento [...]. Ao operar esta passagem da patologia à normalidade, sou levado a propor uma nova nomenclatura para designar essas pesquisas: Psicodinâmica do Trabalho ${ }^{35}$

Dejours $^{35}$ salienta que o desenvolvimento de seus estudos foi possível graças a um duplo diálogo maior: com a Psicanálise e com a Ergonomia. A partir da diferença apontada pela Ergonomia da Atividade, entre trabalho prescrito e trabalho real, Dejours interessou-se pelos elementos organizativos e subjetivos que colaboram para a luta pela saúde, propondo a definição de que "o trabalho é a atividade coordenada desenvolvida por homens e mulheres para fazer face àquilo que, em uma tarefa socialmente considerada útil, não pode ser obtido pela estrita execução da organização prescrita" ${ }^{36}$.

Em seu entendimento, do ponto de vista clínico, trabalho é aquilo que o sujeito deve agregar de si mesmo às prescrições para poder atingir os objetivos que lhe foram determinados ${ }^{37}$. Trabalhar, portanto, é dar conta do hiato, da lacuna que emerge em situação concreta, na medida em que o prescrito, o patrimônio de conhecimento formalmente instituído não é suficiente, exigindo um agir em competência capaz de detectar, interpretar e reagir. Ou seja, este processo exige a mobilização da inventividade e formas de inteligência específicas, às quais Dejours denomina engenhosidade, astúcia ou inteligência da prática, do corpo. Toda atividade de trabalho inclui, portanto, uma forte mobilização subjetiva que, se por um lado é "espontânea", por outro, não deixa de ser extremamente frágil, dependendo da dinâmica entre contribuição e retribuição, envolvendo o julgamento de outrem. O trabalhador espera reconhecimento simbólico da sua contribuição, sem a qual tende a desmobilizar-se, com profundas consequências para sua saúde mental.
Nesta leitura, se a grande contribuição da Ergonomia da Atividade foi demonstrar a defasagem entre trabalho prescrito e trabalho real, a Psicodinâmica do Trabalho sublinhou a inteligência, a forma de inteligibilidade que é colocada em ação, para dar conta deste hiato. Seu objetivo, entretanto, à diferença do que Dejours entende ser o projeto da Ergonomia, não é desvendar a realidade do trabalho humano em suas dimensões físicas e cognitivas, mas a vivência subjetiva.

Para tanto Dejours desenvolveu a estratégia de investigação denominada "Enquete". É interessante assinalar que a respeito do método da Psicodinâmica do Trabalho (PDT), apenas sete anos depois da publicação de seu primeiro livro na França, em 1980, é que encontramos um texto de Dejours sobre o tema. E assim tem sido desde então, é sempre a partir de cobranças da comunidade científica, com quem dialoga e se confronta, que Dejours vem esclarecendo a proposição metodológica de sua corrente, mas sempre o fazendo à distância do gênero manual de método.

Não obstante, no Brasil, por parte de muitos profissionais que se referem ao campo da PDT, raramente encontramos o uso efetivo de sua abordagem metodológica. Justo o contrário, especialmente quanto ao uso de questionários. $\mathrm{O}$ que seria legítimo, desde que precedido por uma análise crítica da proposta do autor, argumentando pela dissociação operada entre a teoria e o método da PDT.

Ao aproximar-se de sua proposição metodológica verifica-se que ela tem como ponto de partida uma demanda. Antes de seguir adiante, vale registrar que encontra-se aqui um ponto nevrálgico de discordâncias no Brasil, pois para muitos, esperar que uma demanda chegue a ser formulada ao especialista, não permite enfrentar a gravidade dos problemas em curso na realidade brasileira.

Por outro lado, pode-se assinalar aqui um ponto comum de interesse com a Ergonomia e, principalmente, com a corrente da Análise Institucional $^{38}$. Trata-se do primado do trabalho da demanda. A demanda - quem a formula, qual seu conteúdo - passa por uma análise. A análise da demanda é fundamental e integra a fase denominada por Dejours de Pré-enquete.

Nunca se vai só para este tipo de empreendimento. Define-se uma equipe de intervenção, formada ad hoc por profissionais de pesquisa (um grupo interdisciplinar, contando com dois ou três pesquisadores, ao menos um com formação extraPDT) que participará diretamente. A esta equi- 
pe se agrega outra, também profissional, de apoio externo (ou de fora), que confere um olhar particular, pela sua exterioridade, à dinâmica em curso. Uma terceira equipe de enquete incorpora, do interior da empresa/empreendimento, os protagonistas daquele meio, voluntários para a operação da enquete. Este coletivo de pilotagem interna é, com frequência, composto por trabalhadores que participam de dispositivos já existentes no trabalho (no Brasil seriam, por exemplo, membros da Comissão Interna de Prevenção de Acidentes - CIPA). Dejours ${ }^{37}$ considera tratar-se de um coletivo da maior importância, pois deve construir condições para prosseguir a ação com autonomia, independente dos especialistas contratados.

No momento inicial busca-se informações sobre o processo de trabalho, suas transformações, o que supõe acesso a documentos de diversos tipos, referentes à empresa/empreendimento. Em seguida, é preciso ter acesso ao meio de trabalho, visitar a empresa/empreendimento acompanhados por diferentes guias (gerentes, engenheiros e médicos, sindicalistas, trabalhadores de base). Enfim, trata-se de abordar a organização (real) do trabalho, assim como conhecer a história de tensões e conflitos neste meio de trabalho, chegando a compreender sua dinâmica. Pode-se registrar também aqui a existência de pontos em comum com a análise global da AET, mas Dejours incide uma diferença, pois seu objetivo não seria:

chegar a uma descrição objetiva da relação homem-trabalho [...] (mas) obter a base concreta necessária para compreender do que falam os trabalhadores que participam da pesquisa e ter uma representação, em imagens, das condições ambientais do sofrimento ${ }^{34}$.

O momento da Enquete propriamente dita desenvolve-se em um local identificado com o trabalho, reunindo o coletivo de pesquisa em torno das relações entre organização do trabalho e sofrimento psíquico, tendo já passado por uma reformulação da demanda inicial. Pede-se então aos trabalhadores que deem suas próprias explicações e interpretações dos fatos que levaram à demanda. A ênfase encontra-se na linguagem, nas falas, nos comentários verbais sobre o conteúdo de sua demanda e não na objetividade dos fatos.

Destaca-se aqui um ponto em comum com o Movimento Operário Italiano - MOI: o crédito na importância do caráter homogêneo do grupo de trabalho, "que compartilham as mesmas condições de trabalho e têm laços orgânicos entre si”', bem como em tudo aquilo que é objeto de consenso (o MOI entende que os resultados devem passar por validação consensual, a fim de que reflitam a experiência coletiva).

Finalmente, a validação e a refutação estão relacionadas ao que emerge com caráter de comentário (entendendo-o como a forma de pensar dos trabalhadores sobre sua situação, através dos quais se tem contato com seus processos de subjetivação) e interpretações (justas ou não, que fazem ou não avançar o debate). $\mathrm{O}$ cuidado com que deve ser conduzido este debate, para que não se cometa nenhuma violência simbólica, chama a atenção do quanto a subjetividade do pesquisador encontra-se engajada na técnica, aproximando-se do que se entende por "implicação" na Análise Institucional ${ }^{39,40}$.

Outro ponto destacado refere-se à definição do que constitui o material da enquete, considerado por Dejours a parte mais difícil. Ele é resultado de uma exploração realizada no interior do que foi antes discutido pelo coletivo. Para Dejours $^{35}$, poder falar com alguém é a forma mais potente de pensar a experiência vivida subjetivamente e, no caso do grupo, um meio de elaboração coletiva das experiências e ainda um "operador de construção do próprio coletivo".

\section{O Modelo Operário Italiano de luta pela saúde (MOI) e o dispositivo Comunidade Científica Ampliada (CCA)}

Na Itália, nas décadas de 1960 e 1970, no contexto da emergência e afirmação do movimento sindical como principal protagonista na transformação social, com a contribuição significativa de Ivar Oddone e Alessandra Re, construiu-se uma proposta de análise-intervenção ancorada em um modelo operário de conhecimento e em outra psicologia do trabalho, centrados na valorização da experiência dos trabalhadores.

Comentando um livro de Oddone et al. ${ }^{41}$, ainda não publicado no Brasil ("Experiência operária, consciência de classe e psicologia do trabalho"), Clot $^{42}$ afirma que o que chamou atenção dos pesquisadores italianos foi o fato de que, paradoxalmente, os operários em geral referiamse ao seu trabalho como algo que os estimulava e desafiava. Assim, mais do que destacar a alienação, constrangimentos, impossibilidades ou limitações dos trabalhadores, a equipe liderada por Oddone preocupou-se em compreender as perspectivas que os trabalhadores criavam para si, procurando subsidiar os coletivos de trabalho em suas tentativas de manter e, sobretudo, alargar seu campo de ação. 
Eles consideraram duas vias para reduzir a nocividade do ambiente de trabalho: a modificação do papel do especialista em saúde assalariado da empresa e/ou novos critérios de definição dos índices de nocividade e de formas de participação operária. Se antes estes critérios tinham a pretensão de neutralidade científica, desenvolvidos por técnicos qualificados, mas "estrangeiros" ao trabalho, Oddone introduziu a percepção subjetiva do trabalhador em relação aos riscos de seu próprio trabalho, rompendo tanto com a concepção marxista de alienação como com a Psicologia do Trabalho subordinada ao taylorismo. Com a primeira por esta entender que a conscientização do trabalhador vem de fora; com a segunda por negar que os trabalhadores tenham quaisquer capacidades de aprendizagem.

Como nos coloca Vicenti ${ }^{43}$ :

Para I. Oddone trata-se de travar um duplo combate, ideológico, no campo da política, e disciplinar, no campo científico, pois ele desejava renovar a psicologia do trabalho no sentido de uma psicologia concreta, fundada sobre a noção de experiência.

Para fazer do conceito de experiência um instrumento-chave, Oddone seguiu uma abordagem teórica e outra experimental. Do lado teórico privilegiou os estudos da Psicologia históricocultural dita soviética (Bassine e Leontiev) naquele período disponível, concomitante à construção com os trabalhadores de um método que lhes permitissem a tomada de consciência de suas experiências, visando uma maior autonomia no trabalho ${ }^{43}$.

O método desenvolvido por Oddone et al. ${ }^{44}$, conhecido por "modelo operário de conhecimento", ou método de produção de conhecimento para a ação dos trabalhadores em uma sociedade capitalista, tem como base quatro pressupostos, na forma de conceitos: o grupo homogêneo, a experiência (ou subjetividade) do trabalhador, a validação consensual e a não delegação.

O grupo tem um caráter homogêneo na medida em que vive submetido à mesma nocividade, acumulando um saber epidemiológico leigo sobre seu ambiente de trabalho. Assim, o ponto de partida é a observação espontânea operada pelos trabalhadores sobre as relações entre as condições e as formas de organização do trabalho e a saúde coletiva, o que se patrimonializa na forma de uma experiência, contudo não estruturada, para o que a pesquisa poderia contribuir. A validação consensual é o julgamento coletivo pelo qual o grupo valida a experiência de cada trabalhador em relação às condições e formas de or- ganização do trabalho, sendo que o conjunto de julgamentos subjetivos e qualitativos dos trabalhadores é transformado em critério de avaliação quantitativa e científica. O conceito de não delegação exprime a recusa em deixar exclusivamente na mão dos gerentes, especialistas, ou mesmo representantes sindicais, o julgamento sobre a nocividade das condições de trabalho do grupo e a fixação dos padrões e limites de nocividade. Isto não significa que o ponto de vista científico, dos saberes disciplinares, não merece importância. Ao contrário, ele é fundamental como saber a ser partilhado com os trabalhadores para que eles possam guiar suas ações na defesa e produção de (mais) saúde no trabalho ${ }^{44}$.

O objetivo metodológico fundamental desta proposta é introduzir a percepção subjetiva do trabalhador como critério de avaliação da nocividade, sem delegar estes critérios exclusivamente a especialistas ${ }^{45}$. No livro em que apresenta esta proposta metodológica, amplamente difundido no Brasil em um dado momento histórico, Oddone et al. ${ }^{44}$ propõem, com os materiais da pesquisa, a elaboração de mapas de risco, o que daria base para a construção de uma pauta de reivindicações concreta e sistematicamente sustentada.

Classificam os fatores de nocividade em quatro grupos de risco. O Grupo 1 integra os riscos físicos, que estão presentes onde o homem vive, seja sua casa ou trabalho (luz, ruído, temperatura). O Grupo 2 engloba os riscos químicos, presentes apenas na fábrica (poeira, gás, vapores). Já o Grupo 3 está relacionado à fadiga, aos esforços muscular e físico, enquanto o Grupo $4 \mathrm{diz}$ respeito aos fatores estressantes ou psicossociais, associados ao trabalho. Considerando estes quatro grupos, a pesquisa protagonizada pelos trabalhadores, passa por três etapas: observação espontânea do ambiente de trabalho; quantificação dos riscos (mapa de risco); e pauta de reivindicações.

Para Oddone, estava claro que os trabalhadores desenvolvem um saber a partir da experiência de trabalho sem, muitas vezes, sequer perceber, valorizar, potencializar ou conseguir transmitir esta experiência. Assim, procurou desenvolver métodos que pudessem auxiliar tanto na formalização, como na transmissão da chamada experiência operária. É neste sentido que introduz a ideia de uma "comunidade científica ampliada", onde o objetivo é colocar em diálogo os saberes da experiência dos trabalhadores e os saberes científicos.

Outra contribuição importante do grupo de Oddone, diz respeito aos métodos indiretos de 
investigação. Impedidos de entrar na fábrica, em uma intervenção conduzida nos anos 1970, junto aos trabalhadores da Fiat, os pesquisadores inovaram, criando o dispositivo de "instrução ao sósia”. Como nos explica Clot ${ }^{46}$ :

[...] o exercício de 'instrução ao sósia' implica um trabalho de grupo no curso do qual um sujeito voluntário recebe a seguinte tarefa: 'Suponha que eu seja seu sósia e que amanhã eu deva substituir você em seu trabalho. Que instruções você deveria me transmitir para que ninguém perceba a substituição?

A função do sósia, nesta técnica, é o de "resistir à atividade", ou seja, colocar-se enquanto leigo, questionando e colocando em foco o "como fazer", para além das prescrições. Com isso, o trabalhador é convidado a pensar sobre aquilo que é executado de maneira automática e habitual, que parece simples, mas que ao ser detalhado, permite vislumbrar o quanto de inédito, criativo e específico há em cada atividade de trabalho. Além disso, ao tentar colocar em palavras sua experiência, o trabalhador pode se dar conta de saberes insuspeitados, alargando seu poder de ação sobre o trabalho ${ }^{42}$.

Cabe ressaltar a forte influência deste modelo na constituição do campo da Saúde do Trabalhador na América Latina e no Brasil, sobretudo em relação ao "mapa de risco", que alcançou tamanha popularidade no meio acadêmico e sindical que hoje está incluído na legislação regulamentadora da saúde no trabalho (NR). Já no Brasil, a outra contribuição - o dispositivo Comunidade Científica Ampliada (CCA), especialmente a técnica de "instrução ao sósia" - que se mantém até hoje operante na França, com desenvolvimentos (como a autoconfrontação cruzada, formulada por Faïta e Clot) só tem tido algum destaque posteriormente, quando a cartografia de risco já perdera a memória da contribuição italiana ${ }^{47}$.

\section{O paradigma ergológico, com o Dispositivo Dinâmico de Três Polos (DD3P) e uma de suas configurações no Brasil: a "Comunidade Ampliada de Pesquisa" (CAP)}

No sudeste da França, até hoje se desenvolve uma importante experiência na região de Bouches du Rhône, na tradição mutualista do campo da saúde, sob direção de M. Andéol e G. Igonet ${ }^{48}$, com a permanente supervisão de Oddone, até seu falecimento em 2011. Exatamente nesta linhagem que vai de G. Canguilhem a A. Wisner, I. Oddone e P. Freire, é que na Universidade de Aix-en-Provence - com a liderança de Y. Schwartz, D. Faïta e B. Vuillon, na companhia de J. Duraffourg e um grupo de trabalhadores industriais da região foi sendo engendrado, desde o final dos anos $1970^{49}$, aquilo que, posteriormente, configurouse como o paradigma ergológico ${ }^{50}$.

Especialmente, o dispositivo por Oddone designado Comunidade Científica Ampliada (CCA) foi inspirador dos primeiros desenvolvimentos. Não obstante a percepção de sua enorme relevância, a análise por que passou com Schwartz ${ }^{51}$ levou a identificar limitações na proposta e no termo CCA, conduzindo-os a construírem outra proposta. Primeiro, o campo dos atores, alertando que "os parceiros não são mais somente militantes operários como no início, são também desempregados, agentes de serviços, funcionários especializados, consultores e profissionais de diversos ramos" ${ }^{50}$. Assim, amplia-se a ideia de "trabalho operário" para a concepção mais geral de trabalho, atividade humana dentre outras. Segundo, apontando a contradição conceitual presente na denominação comunidade científica ampliada que, ao querer incluir os trabalhadores na produção de saberes sobre o trabalho, permaneceu vinculando o conhecimento à ciência (inclusive em sua insígnia). Schwartz entende que encontra-se aí presente uma ideia fraca de ciência, como se fosse o caso de ampliar seus produtores, como se os trabalhadores, como iguais, pudessem fazer parte de uma comunidade cientifica. Enfim, se para Oddone, quem podia fazer a "costura" entre os saberes científicos e os saberes da experiência, seria a "consciência de classe", representada pelo sindicato, para Schwartz, não necessariamente. O que importava era a descoberta que haviam feito de uma tripolaridade.

A partir destas considerações, Schwartz ${ }^{50}$ propõe o Dispositivo Dinâmico de Três Polos (DD3P), como uma perspectiva epistemológica, com implicações metodológicas, não se caracterizando estritamente como método de pesqui$\mathrm{sa}^{33}$. O DD3P pode ser referido como um espaço de encontros, que coloca (ou dispara) um movimento, sempre dinâmico (posto que não é estático ou estável, tampouco visa ao equilíbrio), entre os saberes disciplinares das ciências (polo 1) e os que se sustentam e desenvolvem na experiência (polo 2), costurados por um terceiro, fundamental, o das exigências éticas e epistemológicas que exige e permite exercitar uma certa humildade epistemológica necessária, tanto por parte dos pesquisadores, como dos trabalhadores, para 
aprender uns com os outros. Uma aprendizagem que se faz também na forma de uma (in)prendizagem ${ }^{50}$.

Apresentando didaticamente estes três polos, poderíamos assim defini-los:

. Polo dos saberes organizados e disponíveis: é o dos saberes disciplinares das ciências que ajudam a compreender $\leftrightarrow$ transformar o trabalho. Ciências Econômicas e Políticas, Humanas e da Linguagem, Jurídicas e Sociais, Ciências da Saúde e das Engenharias, Filosofia, todas podendo ser mobilizadas e mobilizar-se, contribuindo com conceitos e métodos para a análise do trabalho, do ponto de vista da atividade.

. Polo dos saberes investidos na atividade: são os que se (re)produzem na e a partir da experiência direta cotidiana, alimentando-se muito com o que é gerado na atividade. Aí se encontram as forças de convocação dos saberes disciplinares para o diálogo, assim como as forças de validação. É neste diálogo sinérgico que os saberes disciplinares são colocados à prova em outro laboratório, mediante a confrontação metódica com as situações concretas em que se dão as atividades, podendo ou não ser validados e, quiçá, desenvolvidos.

. Polo das exigências éticas e epistemológicas: é a abertura e a disponibilidade, tanto ética como epistemológica, de cada participante do processo, para realizar esta troca.

O DD3P colabora para permitir o vaivém entre o conhecimento e a experiência, entre a generalização e a singularização. Parte-se da experiência singular dos protagonistas do trabalho em foco "para, ao longo do tempo, extrair os saberes gerais formalizados nas disciplinas", em um entendimento de que "todo conhecimento tem vocação para ser generalizado" ${ }^{2}$. Ao mesmo tempo, um modelo só é válido quando encarnado, aplicado no aqui e agora, de acordo com a especificidade de cada situação de trabalho. A experiência ou atividade de trabalho, assim, singulariza e atualiza o modelo, conforme nos aponta Durrive ${ }^{52}$ :

Falamos de dispositivo dinâmico de três polos, quando um movimento é articulado, é uma espiral que leva de uma experiência com um nivel de antecipação cada vez melhor a um conhecimento cada vez mais ligado à realidade.

No entanto, o risco presente quando nos propomos a este tipo de diálogo sinérgico é cair em um confronto do tipo teoria X prática, em uma tendência de que os saberes da experiência sejam "engolidos" pelos acadêmico-científicos constituídos, mais valorizados, autorizados e disponí- veis. Assim, a primeira exigência é a humildade epistemológica diante da complexidade que envolve os mundos do trabalho e das atividades que os constituem e desenvolvem. Em seguida, é necessário rigor para poder dar corpo (e voz) às experiências de trabalho. Isto porque a finalidade deste diálogo não é apenas constatar a complexidade e a singularidade que cada um vivencia em sua situação de trabalho, mas também realizar um esforço de verbalização e possível generalização da experiência. As exigências éticas e epistemológicas, imprescindíveis para este diálogo, portanto, dizem respeito à humildade, diante da complexidade das experiências; e ao rigor, diante da exigência de verbalizar o trabalho ${ }^{52}$.

Considerando este debate e as contribuições já apresentadas, em especial a proposição de Oddone atravessada pelas considerações críticas de Schwartz, somadas ao patrimônio da Educação Popular referida em Paulo Freire, pesquisadores brasileiros ${ }^{45}$ no final dos anos 1990 sugerem um dispositivo denominado de Comunidade Ampliada de Pesquisa - CAP (aqui o campo ampliado é o da pesquisa e não o científico), pensada enquanto uma rede de encontros de saberes, reunindo pesquisadores e trabalhadores, onde circula uma comunidade dialógica ${ }^{53}$, em uma coanálise sobre os processos de trabalho, subjetivação e saúde.

\section{Concluindo}

Para Dejours ${ }^{54}$, o termo clínica designa "uma démarche que parte do campo, se desdobra no campo e retorna constantemente ao campo". Já de acordo com Clot e Leplat ${ }^{55}$, as características essenciais do método clínico envolvem considerar seu objeto de estudo em sua globalidade, examiná-lo em profundidade e em toda sua complexidade, conferindo uma importância particular ao papel do(s) sujeito(s).

Representa uma forma de produção de conhecimento pertinente ao caráter enigmático do trabalho contribuindo, portanto, com análise das diferentes formas de mobilização dos trabalhadores. Um recurso metodológico utilizado amplamente, como mostramos aqui, é a constituição de grupos ou comunidades de pesquisa-intervenção, como estratégia de coanálise e de diálogo sinérgico entre saberes.

A dinâmica da confrontação (não se trata aqui de comparação ou oposição, conforme enfatizam Faïta e Maggi ${ }^{56}$ ) já faz parte da tradição da AET, presente também no MOI e desenvolvendo-se com 
Clot e Faïta na abordagem da Clínica da Atividade (com a autoconfrontação cruzada, o que deverá ser apresentada em outro artigo). Trata-se de um conjunto de técnicas que contribuem, inclusive, para a operacionalidade de métodos indiretos. Propostas coerentes com o que a perspectiva ergológica vem procurando dar maior visibilidade e desenvolver, permitindo chegar a algo que as entrevistas em geral não acessam.

Sinalizamos, por fim, que as metodologias aqui analisadas apresentam também o interesse de buscar o desenvolvimento dos possíveis individuais e coletivos. É nesse sentido que observar a atividade do outro para compreendê-la implica em transformá-la, incitando o(s) próprio(s) sujeito(s) a uma atividade interior específica.

\section{Colaboradores}

T Ramminger, M Athayde e J Brito participaram igualmente da concepção e redação do artigo. 


\section{Referências}

1. Minayo-Gomes C, Machado J, Pena P, organizadores. Saúde do trabalhador na sociedade brasileira contemporânea. Rio de Janeiro: Ed. Fiocruz; 2011.

2. Laurell AC, Noriega M. Processo de produção e saúde: trabalho e desgaste operário. São Paulo: Hucitec; 1989.

3. Athayde M. Saúde 'Mental' e Trabalho: questões para discussão no campo da saúde do trabalhador. In: Minayo-Gomes C, Machado J, Pena P, organizadores. Saúde do trabalhador na sociedade brasileira contemporânea. Rio de Janeiro: Ed. Fiocruz; 2011. p. $345-368$.

4. Canguilhem G. O normal e o patológico. Rio de Janeiro: Forense; 2011.

5. Bakhtin M. Problemas da poética de Dostoiévski. Rio de Janeiro: Forense Universitária; 1997.

6. Bakhtin M. Marxismo e Filosofia da linguagem. São Paulo: Hucitec;1986.

7. Sato L, Souza MPR. Contribuindo para desvelar a complexidade do cotidiano através da pesquisa etnográfica em psicologia. Psicol. USP 2001; 12(2):2947.

8. Bosi MLM. Pesquisa qualitativa em saúde coletiva: panorama e desafios. Cien Saude Colet 2012; 17(3): 75-586.

9. Assunção AB, Brito J, organizadores. Trabalhar na saúde: experiências cotidianas e desafios para a gestão do trabalho e do emprego. Rio de Janeiro: Ed. Fiocruz; 2011.

10. Glina D, Rocha LE, organizadores. Saúde Mental no Trabalho: da teoria à prática. São Paulo: Roca; 2010.

11. Bendassoli P, Soboll L, organizadores. Clínicas do Trabalho. São Paulo: Atlas; 2010.

12. Marx K. O questionário de 1880. In: Thiollent M, organizador. Crítica metodológica, investigação social e enquete operária. São Paulo: Polis; 1982. p. 249-256.

13. Bidet P, Pillon TH, Vatin F. Sociologie du Travail. Paris: Montchrestien; 2000.

14. Engels F. A Situação da Classe Trabalhadora na Inglaterra. São Paulo: Global; 1985.

15. Ferreira LL. À propos de l'enquête ouvrière de Kar Marx (1880). Martin Média/Travailler [periódico na Internet]. 2004 [acessado 201306 set];2(12):1114. Disponível em: http://www.cairn.info/revue-travailler-2004-2-page-15.htm

16. Freire P, Faundez A. Por uma Pedagogia da Pergunta. Rio de Janeiro: Paz e Terra; 1985.

17. Boal A. Teatro do oprimido e outras poéticas políticas. Rio de Janeiro: Civilização Brasileira; 2005.

18. Thiollent M, organizador. Crítica metodológica, investigação social e enquete operária. São Paulo: Polis; 1982.

19. Teiger C. O trabalho, esse obscuro objeto da Ergonomia. In: Castillo JJ, Villena J, organizadores. Ergonomia: conceitos e métodos. Lisboa: Dinalivros; 2005.

20. Leplat J, Hoc JM. Tarefa e atividade na análise psicológica de situações de trabalho. In: Castillo JJ, Villena J, organizadores. Ergonomia: conceitos e métodos. Lisboa: Dinalivros; 2005.
21. Montmollin M. Ergonomias. In: Castillo JJ, Villena J, organizadores. Ergonomia: conceitos e métodos. Lisboa: Dinalivros; 2005.

22. Wisner A. A inteligência no trabalho. São Paulo: Fundacentro; 1994.

23. Guérin F. L'activité de travail. In: Kergoat J, Boutet J, Jacot H, Linhart D, organizadores. Le Monde $d u$ Travail. Paris: La Decouverte; 1998. p. 173-179.

24. Brito J. Trabalho e Saúde Coletiva: o ponto de vista da atividade e das relações de gênero. Cien Saude Colet 2005; 10(4):879-890.

25. Botechia FR. O desafio de compreender-desenvolver um regime de produção de saberes sobre o trabalho e suas relações: a "Comunidade Ampliada de Pesquisa" [dissertação]. Rio de Janeiro: UERJ; 2006.

26. Daniellou F. Questions épistémologiques autour de l'ergonomie. In: Daniellou F, organizador. L'ergonomie en quête de ses principes. Débats épistémologiques. Toulouse: Octares Editions; 1996. p. 1-17.

27. Daniellou F. Le statut de la pratique et des connaissances dans l'intervention ergonomique de conception. Document de synthèse pour l'habilitation à diriger des recherches. Toulouse: Université de Toulouse; 1992.

28. Hubault F. Do que a Ergonomia pode fazer a análise? In: Daniellou F, organizador. A ergonomia em busca de seus princípios. São Paulo: Blucher; 2004. p. 105-140.

29. Le Guillant L. Le drame humain du travail: Essais de psychopatologie du travail. Paris: Érès; 2006.

30. Le Guillant L. Quelle psychiatrie por notre temps? Travaux et écrits de Louis Le Guillant. Paris: Érès; 1984.

31. Billiard. Santé Mentale et travail. Paris: La Dispute; 2001.

32. Zambroni-de-Souza P, Athayde M. A Contribuição da abordagem clínica de Louis Le Guillant para o desenvolvimento da psicologia do trabalho. Estud. Pesqui. Psicol. 2006; 6(1):6-19.

33. Athayde M, Muniz H, França M, Figueiredo M. A perspectiva da Ergologia e o campo da Saúde Mental e Trabalho. In: Glina D, Rocha LE, organizadores. Saúde Mental no Trabalho: da teoria à prática. São Paulo: Roca; 2010. p. 229-47.

34. Dejours C. Note de travail sur la notion de souffrance. In: Dejours C, organizador. Plaisir et Souffrance dans le travail. Paris: AOCIP, CNRS; 1987. p. 115-124.

35. Dejours C. Addendum. In: Lancman S, Sznelwar LI, organizadores. Christophe Dejours: da psicopatologia à psicodinâmica do trabalho. Rio de Janeiro: Fiocruz; 2004. p. 47-104.

36. Dejours C. Le facteur humain. Paris: PUF; 1995.

37. Dejours C. Travail vivant 2: Travail et émancipation. Paris: Payot; 2009.

38. Baremblitt G. Compêndio de Análise Institucional e outras correntes: teoria e prática. Rio de Janeiro: Rosa dos Tempos; 1992.

39. Rocha D, Deusdará B. Contribuições da Análise Institucional para uma abordagem das práticas linguageiras: a noção de implicação na pesquisa de campo. Cad Letr UFF 2010; 40:47-73. 
40. Ferrato D. L'analyse de l'implication - vers de nouveaux modes de recherche en sciences sociales. Paris: Harmattan; 1994.

41. Oddone I, Re A, Briante G. Redécouvrir l'expérience ouvrière: vers une autre psychologie du travail? $\mathrm{Pa}-$ ris: Eds. Sociales; 1981.

42. Clot Y. Ivar Oddone: os instrumentos de Ação. Les Territoires du Travail: les continents de l'experience 1999; (3). (Tradução de Milton Athayde e Cláudia Osório).

43. Vicenti A. Ivar Oddone, intelectual orgânico e pesquisador heterodoxo. Les Territoires du Travail: les continents de l'experience 1999; (3).

44. Oddone I, Marri G, Glória S. Ambiente de Trabalho: A luta dos trabalhadores pela saúde. São Paulo: Hucitec; 1986.

45. Brito J, Athayde M, Neves MY. Programa de Formação em Saúde, Gênero e Trabalho nas Escolas: Cadernos de Método e Procedimentos. João Pessoa: Editora UFPb; 2003.

46. Clot Y. A função psicológica do trabalho. Petrópolis: Vozes; 2006.

47. Brito J. Saúde do trabalhador: reflexões a partir da abordagem ergológica. In: Brito J, Figueiredo M, Athayde M, organizadores. Labirintos do trabalho: interrogações e olhares sobre o trabalho vivo. Rio de Janeiro: DP\&A; 2004. p. 91-114.

48. Loriol M. Une expérience française: La Mutualité desBouches-du-Rhône. In: Oddone I, Re A, Brianti G, organizadores. Redécouvrir l'expérience ouvrière: vers une autre psychologie du travail? Paris: Eds. Sociales; 1981.

49. Schwartz Y, Faita D, organizadores. L'Homme producteur. Paris: Eds. Sociales; 1985.

50. Schwartz Y. A comunidade científica ampliada e o regime de produção de saberes. Rev Trab Educ 2000; 7:39-46.

51. Schwartz Y. Expérience et connaissance du travail. Paris: Messidor, La Dispute; 1988.

52. Durrive L. Pistas para o ergoformador animar os Encontros sobre o Trabalho. In: Schwartz Y, Durrive L, organizadores. Trabalho e Ergologia: conversas sobre o trabalho humano. Niterói: EdUFF; 2010. p. 309-318.

53. França MB. Uma comunidade dialógica de pesquisa: atividade e discurso em guichê hospitalar. São Paulo: FAPESP, EDUC; 2007.

54. Dejours C. Psychologie clinique du travail et tradition compréhensive. In: Clot Y, organizador. Les histoires de la psychologie du travail. Toulouse: Octarès; 1996. p.157-183.

55. Clot Y, Leplat J. La méthode clinique en ergonomie et en psychologie du travail. Le travail humain 2004; 68:289-316.

56. Faita D, Maggi B. Un débat em analyse du travail. Tolouse: Octarès; 2007. 